ARTIGO

\title{
Avaliação de desempenho docente: culpar, punir ou desenvolver profissionalmente?
}

\author{
José Rubens Lima Jardilino ${ }^{a}$ \\ Ana Maria Mendes Sampaio ${ }^{b}$ \\ Andressa Maris Rezende Oliveri ${ }^{c}$
}

\section{Resumo}

Esse artigo tem por objetivo discutir a ADD - Avaliação de Desempenho Docente, sob a perspectiva do DPD - Desenvolvimento Profissional Docente, mediante dados levantados em pesquisa realizada junto ao Grupo de Pesquisa Formação e Profissão Docente, do Programa de Pós-Graduação em Educação, da Universidade Federal de Ouro Preto. As análises apresentadas são resultados de grupos focais, realizados com 27 professores da rede pública municipal de ensino da cidade de Mariana - MG. Os resultados apontam que a $\mathrm{ADD}$, quando alicerçada na valência formativa com fins de desenvolvimento profissional, configura-se como uma importante política, no contexto educacional. Entretanto, por vezes, a mesma vem sendo restrita a veículo de domínio e de controle do sistema sobre as carreiras dos professores. Realidade que desperdiça a promoção de mudanças nas práticas pedagógicas e no contexto socioeducativo.

Palavras-chave: Avaliação de Desempenho Docente. Desenvolvimento Profissional Docente. Carreira Docente.

\section{Introdução}

O presente artigo aborda a $\mathrm{ADD}^{1}$ - Avaliação de Desempenho Docente sob a perspectiva de DPD - Desenvolvimento Profissional Docente, enquanto estratégia política para promover a qualidade de ensino. Atualmente, a ADD tende a refletir sobre alguns contextos de influências que a cerca, a exemplo da sociedade civil, da academia, da mídia dominante e, também, de organizações internacionais. A

\footnotetext{
a Universidade Federal de Ouro Preto, Mariana, MG, Brasil

b Universidade Federal de Ouro Preto, Mariana, MG, Brasil

c Universidade Federal de Ouro Preto, Mariana, MG, Brasil

A partir daqui, serão utilizadas somente as siglas ADD e DPD para designar, respectivamente, Avaliação de Desempenho Docente e Desenvolvimento Profissional Docente.
} 
influência da sociedade civil decorre do debate presente no âmbito dos movimentos sociais pela Educação. Outras influências advêm das Instituições de Ensino Superior, estudando a problemática da qualidade de ensino na Educação brasileira e também da discussão suscitada pela grande mídia, acerca dos dados divulgados sobre a realidade educacional do país. Porém, talvez a maior influência, como sempre acontece no Brasil, não somente na área da Educação, seja a decorrente de organismos internacionais (Organização para a Cooperação e Desenvolvimento Econômico - OCDE, Organização das Nações Unidas para a Educação, a Ciência e a Cultura - Unesco, Banco Mundial, Fundo Monetário Internacional - FMI), fundada em indicadores mundiais sobre a problemática educacional que, por sua vez, possibilitam a comparação entre as nações.

No tocante ao processo educativo, a política avaliativa, ditada pelas leis da globalização que marcam a obrigatoriedade de adesão a uma cultura de avaliação, tem-se estendido a currículos e programas, escolas, conhecimentos dos alunos e profissionais da Educação. Não obstante ser um desafio "não só difícil, mas, também, de certa maneira, explosivo" (HADJI, 1995, p. 27), a avaliação dos professores é hoje uma questão incontornável:

A partir do momento em que se admite no domínio das "coisas" da Educação, como de uma maneira geral no campo das práticas sociais, a necessidade de avaliar, não se vê como é que os professores possam escapar a essa regra geral (HADJI, 1995, p. 27).

No Brasil, as pressões da sociedade civil por uma Educação Básica de qualidade, em grande parte, vêm ocorrendo devido ao baixo índice de desempenho dos alunos nas avaliações de larga escala, além da divulgação de estudos comparativos internacionais acerca de políticas que promovem o sucesso escolar. Tais pressões parecem resultar na formulação e na implementação de políticas públicas voltadas para o delineamento do perfil de um bom professor e monitoramento da atuação dos mesmos nas redes de ensino.

Desse contexto, infere-se que a racionalidade existente nas políticas educacionais do país tem considerado o docente como agente essencial para o avanço da qualidade de ensino e demandando que o trabalho e a capacitação desses profissionais sejam avaliados. Vem daí a inspiração para elaboração de planos de carreira que privilegiam a adoção da ADD.

No entanto, a crescente inserção da ADD nos planos de carreira do magistério tem acarretado diversos posicionamentos entre os professores. Essa realidade 
requer, por parte das Secretarias de Educação (estaduais e municipais), uma maior atenção na forma como ocorre a elaboração, a implementação e o retorno regularizado das avaliações para os docentes, com vista a propiciar o seu desenvolvimento profissional.

Percebe-se, ainda, que a razão de ser da ADD, além de fomentar resistências de várias naturezas por parte dos docentes, tem afetado o cotidiano das escolas e gerado um recrudescimento da discussão em volta da questão. Com a implementação da política de ADD em diversas secretarias de Educação, torna-se evidente a existência de certa suspeita e de ceticismo entre os docentes, conduzidos por um clima de "mudança legislada" e não de "mudança negociada" (DAY, 1999, p. 97). Tais mudanças estão ocorrendo de fora para dentro das escolas, o que dificulta as mesmas de contextualizarem com suas diversas realidades.

Esse contexto aponta para a necessidade de a ADD ser vista como um instrumento de DPD, que: a) possibilite a participação dos docentes na elaboração e na implementação de políticas públicas; b) acrescente valor às aprendizagens dos alunos; c) fortaleça o espírito colaborativo entre escola, profissionais da Educação e secretarias de Educação; d) forneça maior credibilidade à profissão docente; e) colabore com a reestruturação do contexto socioeducativo. Não obstante, a aceitação da necessidade e da utilidade da ADD pelos professores serão questionadas.

Frente a essa complexa realidade, esse trabalho investe no objetivo de analisar a política de ADD, uma vez que se relaciona diretamente com o DPD e com mudanças significativas nas redes de ensino. Para tanto, empenharam-se esforços analíticos a partir de relatos de professores da Educação Básica da rede pública municipal de ensino da cidade de Mariana-MG, participantes dessa pesquisa, de abordagem qualitativa e intitulada "Demandas de Desenvolvimento Profissional Docente no Município de Mariana-MG: PNE (2014-2024) e PME (2015-2024)”.

Trata-se de um estudo desenvolvido junto ao Grupo de Pesquisa Formação e Profissão Docente (Foprofi) do Programa de Pós-Graduação em Educação da Universidade Federal de Ouro Preto, certificado no diretório de grupos de pesquisa do Conselho Nacional de Desenvolvimento Científico e Tecnológico (CNPq).

Os dados referendados nesse artigo contaram com a participação de 27 professores da Educação Infantil e do Ensino Fundamental I, da rede municipal de Ensino de Marina - MG. O critério de escolha dos participantes deu-se pelo interesse na formação promovida pelos cursos de pedagogia. 
$\mathrm{Na}$ coleta de dados, foram realizados grupos focais, com foco de discussões em torno de duas categorias de análise: desenvolvimento profissional docente e políticas públicas educacionais. Desse modo, ainda que a referida pesquisa não tenha como foco analítico a ADD, desprenderam-se das falas dos professores sujeitos da pesquisa, indicadores relacionados às demandas da formação e da carreira docente que, por sua vez, encontram-se imbricadas no processo de ADD. A partir desses dados, foram empreendidas as análises presentes nesse artigo.

A primeira seção desse trabalho discute concepções e tendências da ADD, frente à necessidade desse tipo de política ser compreendida e realizada sob a perspectiva de DPD.

A segunda seção empreende uma análise da ADD, tendo como contraponto analítico a perspectiva de DPD, abordagem teórica recente e que vem apresentando, no campo das pesquisas sobre o trabalho docente, importantes resultados ligados ao avanço da qualidade de ensino, focada no corpo docente. Nessa seção, ideias e conceitos sobre DPD são apresentados, em meio a equívocos, contradições e desentendimentos em torno dessa temática.

\section{Avaliação de Desempenho Docente: concepções e tendências}

As proposições de melhoria da política de ADD, adotadas atualmente no país, pouco significado têm se não vierem acompanhadas de uma política mais ampla, fundada na perspectiva de DPD.

Partindo da revisão de literatura, algumas concepções centrais em torno do tema da ADD tiveram destaque nesse estudo. Para Nevo (1990), por exemplo, os conceitos sobre ADD dialogam em torno de quatro perspectivas: 1) avaliação como processo de alcance de determinados objetivos; 2) avaliação como definições descritivas e não judicativas; 3 ) avaliação como recolhimento e exame de informação; 4) avaliação do mérito, sujeita ao valor e à natureza judicativa da mesma.

Cinco anos mais tarde, e em torno desses mesmos conceitos, o autor preza pela possibilidade de união da avaliação de natureza descritiva com a judicativa. Dessa forma, Nevo (1995, p. 135) compreende a ADD como "processo de descrever e julgar o mérito e o valor dos professores, tendo por base o seu conhecimento, competências, comportamento e os resultados do seu ensino". 
Vale destacar que, segundo Scriven (1995), a discriminação entre mérito e valor dialoga com as qualidades intrínsecas (mérito) e extrínsecas (valor). Assim, o mérito pode ser alcançado pelo nível de correspondência com padrões estabelecidos, ou mesmo pela comparação entre avaliados. Enquanto o valor alia o resultado da avaliação a requisitos externos, relacionando-se com necessidades sociais e institucionais.

Desse modo, a noção de mérito conserva-se mais constante por causa da relativa estabilidade das características intrínsecas. Já a noção de valor revela diversas variações relacionadas à interação das pessoas com o contexto (características extrínsecas). Por esse motivo, o contexto local não pode ser ignorado na avaliação do valor. Enquanto a existência de mérito não implica a existência de valor, podendo haver mérito sem valor. Porém, a noção de valor necessita ter implícito algum mérito. Em vista disso, a compreensão de julgamento desempenha um papel primordial em que o importante não é julgar, mas descrever. A perspectiva de avaliação docente como descritiva relaciona-se com a avaliação formativa e entende o julgamento como ponto de chegada, e não de partida.

Apesar de não divergir da perspectiva de avaliação trazida por Scriven (1995), Hadji (1995) afirma que um processo avaliativo deve priorizar quatro dimensões fundamentais: 1) ato de julgamento, que destaca a finalidade da avaliação como possibilidade de adaptação às suas ações e seus objetivos; 2) ato que implica um duplo trabalho de modelização, em que, pela construção de um referente formado por um conjunto de expectativas, estabelece-se um referido com critérios claros e previamente definidos; 3) ato direcionado à tomada de uma decisão, tendo por objetivo aperfeiçoar as posteriores ações em relação ao objeto analisado; 4) ato de comunicação social, em que avaliador e avaliado, através diálogos, buscam respostas sobre a utilidade de suas ações e propostas. Observa-se nessas dimensões, a importância das clarificações que devem ocorrer em volta das finalidades, das expectativas, dos critérios e da interação entre os envolvidos. A compreensão e o significado desses elementos devem-se relacionar, intrinsecamente, com o motivo pelo qual se avaliam os professores, qual seja a (re)tomada de decisões, capazes de (re)orientar e (res)significar o processo de DPD.

No Brasil, a ADD é prevista pela Lei de Diretrizes e Base da Educação (LDB) - Lei no 9.394, de 20 de dezembro de 1996 (BRASIL, 1996), que em seu artigo 67 estabelece a promoção e a valorização dos profissionais da Educação ${ }^{2}$ pelas redes de ensino, por meio de planos de carreira que assegurem: a) ingresso exclusivo por concurso público de provas e de títulos; b) formação profissional contínua; c) cumprimento do

Para uma análise mais ampla das políticas nos estados e municípios sobre a valorização do trabalho docente, confira o trabalho de André (2015). 
piso salarial; d) carga horária reservada para estudos e planejamentos; f) condições de trabalho apropriadas para o exercício da função, além de e) progressão funcional alcançada por meio de titulação e de avaliação de desempenho.

No caso específico do lócus dessa pesquisa, a rede pública municipal de Mariana - MG, a ADD é regulamentada pela Lei Complementar $n^{\circ} 139$, de 29 de abril de 2014 (MARIANA, 2014), que considera tempo de exercício da profissão, progressões horizontal e vertical. A progressão horizontal ocorre por meio da combinação de procedimentos específicos da ADD, e a vertical observa a elevação do nível de escolaridade, seja na área de conhecimento específica de atuação ou em área concordante.

Na mencionada lei, os elementos mais prestigiados interferem sobre o salário. O primeiro é a titulação, responsável pela mudança de nível (promoção vertical), e maior correção salarial no decorrer da carreira. O segundo é a ADD (progressão horizontal), responsável pelas gratificações por produtividade. E o terceiro é o tempo de serviço, responsável por incorporar ao piso salarial um percentual invariável e único de $3 \%$ por quinquênio.

Tendo em vista que a regulação da carreira docente, por meio da ADD, é prevista nos planos de carreira, destaca-se a necessidade de serem elaborados e implementados mediante um processo democrático, amplamente conhecido, discutido e analisado pelos professores. Entretanto, os professores $\mathrm{P}^{2} \mathrm{EFCE}^{3} \mathrm{e}$ P4EIJE destacam que isso não vem ocorrendo na rede de ensino:

Porque a gente vê da mesma maneira que a gente sente: que está sendo enfiado goela abaixo. Como Governo Federal coloca, a gente sente que o Governo Municipal faz a mesma coisa. Tipo assim: isso aqui, você faz! Por favor, não me questione, porque se você questionar você vai falar vazio [...]. Então, eu vejo que essa coisa da imposição, ela continua! Provavelmente, eles têm muito interesse que isso se perpetue por muitos anos (P3EFCE).

Então, é isso que a gente precisa. É ponderar e participar. Porque, assim, a gente não é convidado. Muitas destas discussões, a gente não fica sabendo. Vem de cima para baixo (P4EIJE).

\footnotetext{
No propósito de resguardar o anonimato dos professores envolvidos na pesquisa, foi criado um código, que funciona da seguinte forma: a) a letra $\mathrm{P}$ para professor; b) um número entre 0 a 9, criado nos grupos focais; c) as siglas El (identificando a etapa da Educação Infantil) e EF (para o Ensino Fundamental I), segmentos em que atuam os professores investigados; d) as iniciais das escolas que os professores trabalham; e) a situação funcional do professor, em que a letra $\mathrm{E}$ indica efetivo, a $\mathrm{C}$ indica contratados, a $\mathrm{P}$ indica estágio probatório e a $\mathrm{D}$ indica contratados sob regime de designação.
} 
Destarte, é fundamental que as secretarias de Educação estabeleçam modelos adequados de participação do quadro docente.

Por meio da análise da Lei Complementar n 139, de 29 de abril de 2014 (MARIANA, 2014), o plano de carreira dos professores de Mariana - MG aponta para a tendência da ADD em se destacar como elemento definidor de gratificações firmadas no mérito individual dos docentes e como estratégia política centrada na obtenção de resultados. Essas gratificações ocorrem ora pelos resultados obtidos pelas escolas no alcance das metas estabelecidas pelas secretarias de Educação, ora pelos resultados acadêmicos anuais dos alunos, obtidos nas avaliações bimestrais padronizadas, elaboradas pela SME - Secretaria Municipal da Educação.

Obstante, no alusivo a esse último, a vinculação da qualidade de desempenho do professor à aprendizagem dos alunos não pode ocorrer de forma a desconsiderar outros aspectos do contexto escolar. Um exemplo dessa realidade, é que numa escola com baixos índices de letramento e que não possui biblioteca, a ADD se mostra comprometida, haja vista a falta de mais incentivos à aprendizagem discente. Segundo Medley (1982):

Do mesmo modo que a competência de um professor não garante em absoluto que, em determinadas situações, o seu desempenho vai ser de certa maneira, também não se poderá assegurar que o desempenho do professor, por si só, produza determinado tipo de resultados junto a seus alunos (p. 16).

Quanto aos objetivos da ADD, o professor P1EIJE declara que, por parte da SME, não existe interesse que não seja o da gratificação: "eu acredito que a avaliação do desempenho é usada, unicamente para a questão salarial dos profissionais da Educação". Ou seja, não há qualquer intento formativo voltado para análise, revisão e melhoria do processo de ensino e aprendizagem e para o desenvolvimento profissional dos docentes.

Entretanto, o plano de carreira dos professores de Mariana-MG - Lei Complementar $n^{\circ} 139$, de 29 de abril de 2014 (MARIANA, 2014) - além de interferir na gratificação anual por produtividade, interfere, também, na liberação para especialização stricto sensu e na possibilidade de exoneração dos docentes, caso apresentem, no intervalo de cinco anos, duas avaliações anuais consecutivas de desempenho negativas ou, alternadamente, três avaliações anuais negativas. Desse contexto, sobressai o intento de controle da ADD, em que, caso os docentes que não alcancem os padrões e critérios impostos, podem ser repreendidos, penalizados e, em último caso, exonerados. 
Frente aos objetivos reducionistas que vêm se propagando em torno da ADD, Pacheco e Flores (1999) consideram que os mesmos resultam dos propósitos globais de melhoria da escola, em que conceitos como eficiência e eficácia, associados à competitividade e à produtividade, são os dominantes nos discursos de reforma educativa, sendo a avaliação de desempenho "acionada como suporte de processos de responsabilização ou de prestação de contas relacionados com os resultados educacionais" (AFONSO, 1998, p. 116).

Em oposição às propensões que reduzem a ADD às questões de ordem meramente quantitativas, esse tipo de avaliação deve considerar a essência do objeto a ser avaliado. Assim, a eficácia e a produtividade do professor tornam-se objetos avaliativos, que devem validar pareceres adequados às finalidades, aos procedimentos e às variações do contexto educativo.

Em outras palavras, a ADD não se resume às práticas de controle, devendo associar seus resultados à sua capacidade de fortalecer a qualidade do trabalho prestado. Fato que exige das secretarias de Educação uma diferenciada atenção na forma como decorre o retorno dessas avaliações para os docentes. Essa problemática foi questionada pelo professor P7EIJD:

Como o município utiliza essas avaliações de desempenho que faz com os profissionais da Educação? Como isso é feito? Para onde vai? Você como profissional de Educação, além da nota da escola, você tem um retorno? (P7EIJD).

Compreender a ADD como elemento de DPD exige feedbacks constantes entre avaliados e avaliadores, capazes de redirecionar práticas e posicionamentos, não somente por parte dos docentes, como também das escolas e das secretarias de Educação. Para o professor P3EFCE:

Eles só avaliam a gente. Inclusive, a gente questiona muito isso: a secretaria de Educação nunca é avaliada. É uma avaliação unilateral. O Sistema Público tem que ser uma via de mão dupla (P3EFCE).

Enfatiza-se, assim, que somente por meio de uma avaliação sistêmica é possível apreender os resultados imediatos e mediatos diante dos seus mais diversos efeitos. Além disso, dos processos de elaboração e implementação de avaliação sistêmica desprende-se uma valiosa aprendizagem social, que agrega valor às instituições e ao trabalho realizado por seus profissionais. A Figura 1 apresenta importantes ações empreendidas nesse processo, envolvendo a avaliação de desempenho de gestores e de profissionais da Educação. 
Figura 1 - Avaliação de desempenho

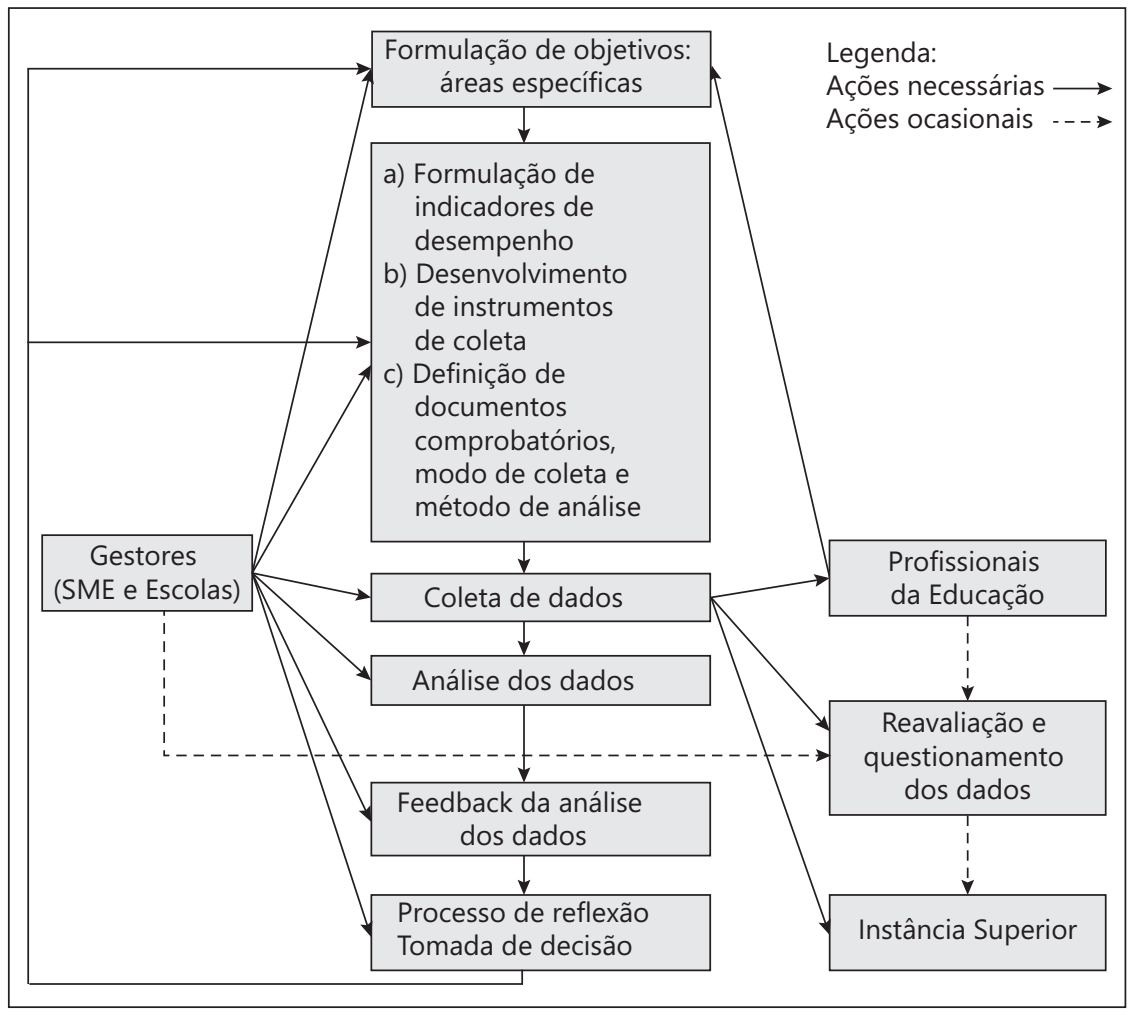

Fonte: Elaborada pelos autores (2019) a partir da pesquisa de Reifschneider (2008, p. 55).

Pensadas anteriormente ao período avaliativo, as duas primeiras fases instauram-se como preparatórias. A primeira volta-se para a formulação dos objetivos, momento em que sobressaem os propósitos da avaliação que será realizada, bem como as áreas específicas que serão atingidas. Na segunda, ocorre o desenvolvimento dos indicadores de desempenho e dos instrumentos de coleta de dados, bem como a definição dos documentos comprobatórios, sobretudo os relacionados à progressão vertical, presentes nos planos de carreira do magistério. De forma democrática, são definidos, também, os instrumentos de coleta de dados e os procedimentos de análise. A partir de então, os dados da avaliação serão coletados dentro de períodos previamente estipulados pelos envolvidos. As análises deverão estar baseadas em critérios claros e coerentes, com o contexto socioeducacional do avaliado. Os resultados das análises deverão ocorrer de forma descritiva e pontual, com vistas à possibilidade de reflexão, tomada de decisão e possível redirecionamento da prática, podendo, inclusive, interferir nas 
duas primeiras fases preparatórias. Havendo discordância quanto às análises e aos feedbacks, haverá uma reavaliação dos dados e, até mesmo, uma instância superior, previamente escolhida para esses casos, poderá será consultada. Assim, as decisões relacionadas ao desenvolvimento profissional e à reorientação de novos planejamentos, conceitos, ideias e posturas, devem estar pautadas nas análises realizadas.

Diante do exposto, pode-se afirmar que as discussões sobre a ADD ocorrem em um contexto de abordagem complexa e apresentam-se como resultado de uma interação de diversos fatores, tanto de natureza profissional como de natureza técnica, política e organizacional, que devem priorizar o objetivo central de promover o desenvolvimento profissional dos professores e avanço da Educação Básica prestada pelas redes de ensino.

\section{Avaliação de Desempenho Docente: na busca pelo Desenvolvimento Profissional Docente}

O conceito de DPD tem recebido diversas perspectivas conceituais (FIORENTINI, CRECCI, 2013; FARIAS; JARDILINO; SILVESTRE, 2012; MARCELO, 2009; MARCELO; VAILLANT, 2009). Por DPD, entende-se o processo que, em longo prazo, permite aos professores alcançar novas aprendizagens e uma melhoria profissional contínua. Nessa perspectiva, a ADD deverá assumir uma vertente formativa, de crescimento e aperfeiçoamento, decorrentes do feedback que o professor vai recebendo e assimilando, numa perspectiva evolutiva. Caso contrário, a percepção da ADD pelos professores se revelará como prestação de contas burocrática e contratual, capaz de produzir o aumento da desconfiança e da desmotivação por parte do profissional.

De um modo geral, tem-se identificado a tensão entre os propósitos formativos da $\mathrm{ADD}$, orientados para o desenvolvimento profissional e os propósitos somativos, pautados na prestação de contas e orientados para decisões de gestão de carreira. Observa-se, também, que as políticas públicas educacionais, a exemplo dos planos de carreira do magistério, têm enfatizado a formação docente como elemento primordial à qualidade do ensino, em detrimento à pouca atenção fornecida à carreira dos professores e ao contexto de atuação desses profissionais, embora, ainda nos dias atuais, exista um considerável déficit na formação continuada prestada pelas secretarias de Educação.

Desse modo, percebe-se que a formação, quando estruturada à margem de outros elementos inerentes ao DPD, aviva a imagem do professor como simples condutor de um saber produzido no exterior de sua profissão. Nesse contexto, é imperioso 
que as políticas públicas educacionais observem: 1) o desenvolvimento interno das escolas para atender à demanda dos alunos; 2) os fluxos idade/série, que não vêm sendo ofertados em consonância com os requisitos necessários; 3) o nível socioeconômico dos alunos; 4) as condições de trabalho; 5) o déficit no apoio aos alunos com deficiência; 6) a infraestrutura das escolas. Todos esses aspectos impactam diretamente nos resultados aferidos na ADD.

Em contraponto à distinção da formação docente no processo de desenvolvimento profissional, Imbernón (2009) expande o conceito de DPD e defende que:

O desenvolvimento profissional é um conjunto de fatores que possibilitam ou impedem que o professorado avance na identidade. A melhoria da formação e a autonomia para decidir contribuirão para esse desenvolvimento, porém, a melhoria de outros fatores (salário, estruturas, níveis de decisão, níveis de participação, carreira, clima de trabalho, legislação trabalhista) também o farão e de forma muito decisiva. Podemos realizar uma excelente formação e depararmos com o paradoxo: um desenvolvimento próximo à proletarização no professorado porque os outros fatores não estão suficientemente garantidos nessa melhoria. E isso repercute, é claro, no desenvolvimento profissional, mas também muito no desenvolvimento pessoal e na identidade (p. 77-78, grifo nosso).

No que diz respeito, especificamente, ao processo de formação continuada dos professores investigados, ressalta-se a importância da interferência dos resultados da ADD nesse processo. Em outras palavras, os objetivos da ADD devem estar ligados às possibilidades de formação profissional docente, tendo em vista que esse tipo de avaliação só faz sentido se comprometido com propósitos formativos. Essa questão implica em melhor compreender a proposta de formação continuada, bem como os incentivos e o amparo pedagógico ofertados aos docentes pela SME.

Segundo os professores investigados, faltam incentivos para que os docentes continuem se formando continuamente. Esse fato fortalece a ideia de criação de um Programa de Formação Continuada Docente, coordenado pela SME, capaz de planejar e de executar as ações formativas voltadas para os professores, bem como os demais profissionais de Educação.

Outra questão em torno da falta de incentivo à formação continuada refere-se à escassez de professores substitutos na rede de ensino. Conforme o professor P5EFCE, "a dificuldade está aí, em nos liberar. Não porque a escola não quer 
liberar, e sim porque não tem pessoas para ficar substituindo". Ainda para o professor P7EFLE: "não tem como um profissional não ficar na sua sala para você fazer curso, ou então, você vai fazer no horário que não é para você estar na escola". Sendo assim, ainda que os professores percebam suas necessidades formativas e, até mesmo, busquem investir na sua formação, veem-se restringidos pelas próprias SME, que não possuem um quadro docente coerente com tais necessidades. Para o professor P5EFLE:

O professor busca formação e aí tem esse problema: que não tem ninguém que o substitua. Você tem que ir buscar formação fora do seu horário, o que é complicado. Porque não posso largar a sala de aula, não posso largar meu horário de pedagogia, não tem quem substitua. Esse é um problema! (P5EFLE).

A realidade trazida pelos professores ratifica as análises realizadas por Davis, Nunes e Almeida (2011):

[...] faltam professores substitutos, quando os docentes se afastam da sala de aula para participar de ações de Formação Continuada e muitas Secretarias de Educação reclamam de que não dispõem de um centro de formação próprio [...] (p. 95).

Como indica o professor P5EFLE, a falta de professores substitutos aventa a chance de que a formação ocorra fora do horário de trabalho. Contudo, as orientações dos Referencias para a Formação de Professores (BRASIL, 2002, p. 135) indicam que as secretarias de Educação devem criar "condições para que a formação continuada possa ocorrer dentro da jornada regular de trabalho dos profissionais da Educação, sem prejuízo das horas de docência".

Quanto à natureza dos cursos ofertados, os professores destacam que esses não contemplam suas demandas formativas, mostrando-se repetitivos e incapazes de transformarem suas práticas. Nota-se, ainda, que, em nenhum momento, os professores relacionaram a formação continuada ao contexto de práticas e experiências, próprias do trabalho pedagógico realizado nas escolas, limitando esse tipo de formação a uma instituição ou a um determinado curso. Além disso, a ADD não foi considerada, por esses profissionais, como instrumento capaz de diagnosticar as demandas formativas e apontar caminhos para saná-las.

Esse quadro contrasta com importantes análises do Banco Mundial (WORLD BANK, 2017) e de Mourshed, Chijioke e Barber (2010), que apontam para a necessidade dos 
países de criarem medidas educativas capazes de elevar, não somente, o currículo, mas o ensino e a prática dos professores a elementos primordiais para a melhoria dos resultados dos alunos. Segundo Hirata, Oliveira e Merebe (2019):

Ao mesmo tempo em que os países de sucesso adotavam essas medidas, também foram desenvolvidas novas estratégias para recrutar e formar melhores professores, o que serviu de base para avançar em suas reformas educativas e no grau de autonomia atribuído às escolas (p. 198).

Ou seja, nesses casos, a formação docente deve ser convergida a alicerce de diversas políticas educativas, a exemplo da ADD. Entretanto, Sampaio (2018) adverte que no Brasil:

A perversa contradição dessa situação está entre a ideia do professor como foco principal do sucesso do sistema educacional, e a imposição vista em várias redes de ensino, para que estes profissionais, por conta própria e sem apoio, atendam aos apelos do governo em "fazer-se competente" (p. 160).

Em grande parte dos casos, é justamente em torno dessa contradição que a ADD vem ocorrendo e, por isso, o seu insucesso. Segundo Day (1999), ainda não foi possível identificar um modelo de ADD alçado de êxito, fato que reflete no descontentamento e na insegurança por parte dos professores envolvidos. Ainda para esse autor, isso ocorre pela falta de critérios essenciais a qualquer modelo de avaliação - validade, fidelidade e utilidade - sem os quais, o alcance de sucesso e de efeito, no tocante ao DPD, torna-se praticamente inexequível. A falta da totalidade desses critérios pode vir a justificar a refutação dos professores no seu processo avaliativo. Ou seja, a validade da avaliação é imediatamente afetada se os procedimentos não são adequados. Por se tratar de uma avaliação, é também um juízo, logo, é subjetiva e, assim, a sua fidelidade pode ser infringida. Quanto à sua utilidade, essa é imediatamente interrogada quando associada à burocracia inerente e aos efeitos que, efetivamente, produz. Sobre os modelos de ADD, Day (2011) acrescenta que:

Os modelos de avaliação concebidos para beneficiarem apenas as necessidades definidas pelas organizações irão, em última instância, conduzir ao afastamento da visão dos professores enquanto profissionais autônomos e responsáveis (que prestam contas), para serem encarados como técnicos que implementam o currículo, em vez de o mediar (p. 173-174). 
Nos modelos de avaliação de cunho burocrático, destaca-se, ainda, a natureza da relação entre avaliados e avaliadores. Esse item se apresenta como ponto nevrálgico em torno das discussões suscitadas entre os professores, tendo em conta: 1) a objetividade de quem avalia e do próprio processo; 2) a formação dos avaliadores; 3) a falta de clareza dos contributos da avaliação para o DPD; 4) a falta de um trabalho colaborativo que preze por momentos de reflexão, formação e troca de experiências.

Outro aspecto importante que interfere nos resultados da ADD trata-se das condições de trabalho. Dentre as queixas recorrentes nas falas dos professores se encontram: 1) falta de material e recursos didáticos; 2) excedente de trabalho burocrático, a exemplo de preenchimento de dados e feitura de relatórios, necessários à ADD; 3 ) escassez de monitores, sobretudo, nas salas que trabalham com crianças menores.

Outros quesitos relacionados às condições de trabalho se interligam: 1) à própria formação docente, a exemplo da falta de tempo para reflexão e sistematização da prática, bem como para estudos individuais e coletivos e 2) liberdade de autonomia. Esse último é retratado pelos professores, que confessam-se restringidos em seu poder de decisão sobre sua prática docente. Quanto à incidência da autonomia em sala de aula, o professor P3EFCE afirma que:

É pouquíssima! Teoricamente, se vê muita coisa que é aplicável, mas a gente se sente engessado. Engessado pelos conteúdos que são exageradamente amplos e a gente não tem como estar fazendo com que o aluno absorva aquilo da melhor maneira. E aí, vem um cronograma de avaliações que já vem da Secretária de Educação. Um cronograma de testes que tem de ser seguido à risca. Entende? Então, por mais que falem: "você fechou a porta, a sala é sua", a coisa não é bem assim. O que a gente precisa é de autonomia para poder se desenvolver (P3EFCE).

A referida perda de autonomia dos professores realça a precarização do seu trabalho e a sua desvalorização pedagógica, política e social, em que pesem os empenhos realizados para sua valorização. De acordo com o exposto pelo professor P3EFCE, as ações em torno dos conteúdos a serem trabalhados com os alunos, inclusive quanto à sua forma, são direcionadas por encaminhamento institucional da SME e cobradas nas ADD.

Essa realidade revela a necessidade de que a ADD seja articulada a um processo de DPD que valorize elementos e direitos de referências para uma boa docência, a exemplo do 
direito de liberdade de ensino e aprendizagem ${ }^{4}$ e, portanto, pela autonomia pedagógica dos docentes. Sem o devido direito de autonomia pedagógica garantido, ainda que alguns professores, mesmo com recursos próprios, invistam na continuidade de sua formação, os critérios impostos para alcance de bons resultados na ADD continuarão a refletir em descontentamento e frustração por parte dos docentes. Para o professor P5EFCE:

A formação até nos frustra. Eu tô emperrada! Do que eu consigo mudar na minha sala, eu consigo. Mas eu tenho que fazer quase que dois trabalhos: eu faço aquilo que eu estudei, que eu vi que é legal, e faço aquilo que a secretaria está pedindo. Porque, no momento da avaliação de desempenho, eu tenho que seguir aqueles critérios que são pedidos. O menino está de "saco cheio" daquele conteúdo, mas eu tenho que continuar, porque a prova é única. Na hora que vem a prova, ele tem que dar conta. Então, aí você começa a trabalhar paralelo. Aí, às vezes, não fica bem nem uma coisa nem outra (P5EFCE).

Percebe-se que, na busca por atingir a gratificação docente, prevista no Plano de Carreira - Lei no 139, de 29 de abril de 2014 (MARIANA, 2014) - e, até mesmo, em preservar os seus cargos, os professores veem-se obrigados a impulsionar os resultados dos discentes. Para tanto, chegam a modificar e a restringir suas propostas pedagógicas e, ainda, a utilizar de modo inadequado, apropriando-se, apenas, dos componentes curriculares exigidos nas avaliações realizadas pela SME. Desse contexto, avultam duas questões: 1) uma matriz de avaliação não pode ser elevada à categoria de currículo, devido ao caráter operacional da primeira, que tem seus conteúdos selecionados e restritos a partir do nível de importância considerado por seus elaboradores; 2) diante da pressão em alavancar os resultados dos alunos pode ocorrer um interesse por parte dos docentes de atuarem em escolas que ofertem melhores condições para alcançar esses resultados.

Frente ao exposto, a ADD se sobressai como importante alicerce formativo e de valorização de professores. Estudos dessa natureza sugerem novos contornos conceituais e processuais a esse tipo de política avaliativa que, por sua vez, deve ser encarada na perspectiva de desenvolvimento profissional docente e de melhoria do processo de ensino e de aprendizagem da Educação Básica no país.

\section{Considerações Finais}

A problemática evidenciada pelos professores investigados e pelas análises realizadas sinaliza a contradição presente no âmbito de uma política pública

${ }_{4}$ Direito previsto pelo Art. 206 da Constituição Federal Brasileira, de 05 de outubro de 1988 (BRASIL, 1988). 
educacional importante ao processo de DPD. Isso porque, na visão dos professores, a ADD ainda não tem produzido impacto significativo para a melhoria do processo de ensino e de aprendizagem, na medida em que não coopera com a formação do quadro docente de forma coerente e efetiva. Esse elemento aponta temas para pesquisas futuras no interior do Foprofi.

Um grande exemplo dessa contradição está na falta de feedbacks constantes aos professores, capazes de promover discussões e reflexões sobre a sua prática. Como agravante, nota-se não existir uma cultura pedagógica colaborativa implementada no interior das escolas.

Como reflexo desse contexto, ocorre o desperdício de mecanismos formativos, concebidos como ponto fulcral do desenvolvimento profissional dos professores, como também, das unidades educativas, tendo em vista que esse tipo de cultura reflete sobre as necessidades das escolas e vai ao encontro de soluções para os problemas e lacunas nelas encontrados. Nesse sentido, a ADD configura-se como uma política educacional capaz de identificar não somente as necessidades formativas e de valorização dos docentes, como, também, de criar indicadores sobre os avanços e as fragilidades das unidades escolares e das próprias SME.

Desse modo, a função formativa da $\mathrm{ADD}$ não pode estar em detrimento à somativa. Caso contrário, a política de ADD ficará marcada apenas como um dispositivo classificatório capaz de gerar tensões e exasperações entre os professores. Com efeito, os professores investigados acreditam que a ADD deve estar mais orientada para o seu desenvolvimento profissional e não tanto para o ajuizamento do seu mérito.

A mudança desse quadro requer que a comunidade escolar, juntamente com as secretarias de Educação empreendam ações que incentivem a responsabilização coletiva pela melhoria da Educação prestada, ao invés de, tão somente, prestigiarem ações com caráter de recompensa ou castigo, mais vistas como veículo de domínio e de controle do sistema sobre as carreiras dos docentes.

Assim, esse estudo permite concluir que o processo de DPD pode encontrar no contexto da ADD ações congruentes de autorreflexão, autoavaliação e autocrítica, que devem se configurar não somente como ferramenta propícia para promover mudanças pedagógicas orientadas pelos docentes, mas, também, suscitará possibilidade de um processo coletivo de reestruturação do contexto socioeducativo. 


\title{
Teacher Performance Evaluation: to blame, punish or develop professionally?
}

\begin{abstract}
This article aims to discuss the Teacher Performance Evaluation, from the perspective of the Teacher Professional Development, based on data collected in research carried out by the Research Group for Teacher Education and Teaching Profession, of the Graduate Program in Education in the Federal University of Ouro Preto. The analysis presented are the results offocus groups, carried out with 27 teachers from the municipal public-school system in the city of Mariana-MG. The results show that Teacher Performance Evaluation becomes an important training policy when focused on teacher professional development. However, this has been restricted to the vehicle of dominance and control of the system over teachers' careers, a fact that wastes the promotion of changes in pedagogical practices in the socio-educational context.
\end{abstract}

Keywords: Teacher Performance Evaluation. Teacher Professional Development. Teaching Career.

\section{Evaluación del Desempeño Docente: ¿culpar, castigar o desarrollar se profesionalmente?}

\section{Resumen}

Este artículo tiene como objetivo discutir Evaluación del Desempeño Docente (ADD), desde la perspectiva del Desarrollo Profesional Docente (DPD), a partir de datos recolectados en una investigación realizada con el Grupo de Investigación de Formación y Profesión Docente, del Programa de Posgrado en Educación de la Universidad Distrito Federal de Ouro Preto. Los análisis presentados son resultado de grupos focales, realizados con 27 docentes del sistema de escuelas públicas municipales de la ciudad de Mariana - MG. Los resultados muestran que la evaluación del desempeño docente, cuando se basa en la valencia formativa para fines de desarrollo profesional, se configura como una política importante en el contexto educativo. Sin embargo, a veces, se ha restringido al vehículo de dominio y control del sistema sobre las carreras de los docentes. Realidad que desperdicia la promoción de cambios en las prácticas pedagógicas y en el contexto socioeducativo.

Palabras clave: Evaluación del Desempeño Docente. Desarrollo Profesional Docente. Carrera Docente. 


\section{Referências}

AFONSO, A. J. Políticas educativas e avaliação educacional. Braga: Universidade do Minho, 1998.

ANDRÉ, M. Políticas de valorização do trabalho docente no Brasil: algumas questões. Ensaio: Avaliação e Políticas Públicas em Educação, Rio de Janeiro, v. 23, n. 86, p. 213-230, jan./fev. 2015. https://doi.org/10.1590/S0104-40362015000100008

BRASIL. Constituição Federal, de 5 de outubro de 1988. Diário Oficial da União, Brasília, DF, 5 out. 1988.

BRASIL. Lei no 9.394, de 20 de dezembro de 1996. Estabelece as diretrizes e bases da educação nacional. Diário Oficial da União, Brasília, DF, 23 dez. 1996.

BRASIL. Ministério da Educação. Referenciais para formação de professores. 2. ed. Diário Oficial da União, Brasília, DF, 18 jan. 2002.

DAVIS, C. L. F.; NUNES, M. M. R.; ALMEIDA, P. C. A. Formação continuada de professores: uma análise das modalidades e das práticas em estados e municípios brasileiros. São Paulo: Fundação Victor Civita: Fundação Carlos Chagas, 2011.

DAY, C. Avaliação do desenvolvimento profissional dos professores. In: ESTRELA, A.; NÓVOA, A. (orgs.). Avaliações em educação: novas perspectivas. Porto: Porto Editora, 1999. p. 95-108.

DAY, C. Desenvolvimento profissional de professores: os desafios da aprendizagem permanente. Porto: Porto Editora, 2011.

FARIAS, I. M. S.; JARDILINO, J. R. L.; SILVESTRE, M. A. Desenvolvimento profissional docente e inovação pedagógica: estudo exploratório sobre contribuições do PIBID. Brasília, DF: OBEDUC/CAPES, 2012.

FIORENTINI, D.; CRECCI, V. Desenvolvimento profissional docente: um termo guarda-chuva ou um novo sentido à formação? Formação Docente, Belo Horizonte, v. 5, n. 8, p. 11-23, 2013.

HADJI, C. A avaliação dos professores: linhas directivas para uma metodologia pertinente. In: ESTRELA, A.; RODRIGUES, P. (coords.). Para uma fundamentação da avaliação em Educação. Lisboa: Colibri, 1995. p. 27-36. 
HIRATA, G.; OLIVEIRA, J. B. A.; MEREB, T. M. Professores: quem são, onde trabalham, quanto ganham. Ensaio: Avaliação e Políticas Públicas em Educação, Rio de Janeiro, v. 27, n. 102, p. 179-203, mar. 2019. https:// doi.org/10.1590/s0104-40362018002701888.

IMBERNÓN, F. Formação permanente do professorado: novas tendências. São Paulo: Cortez, 2009.

MARCELO, C. Desenvolvimento profissional docente: passado e futuro. Sísifo: Revista de Ciências da Educação, n. 8, p. 7-22, jan./abr. 2009.

MARCELO, C.; VAILLANT, D. Desarrollo profesional docente: ¿Cómo se aprende a enseñar? Madrid: Narcea, 2009.

MARIANA. Lei Complementar $n^{\circ} 139$, de 29 de abril de 2014. Dispõe sobre o plano de carreira do pessoal do magistério, secretaria escolar e inspeção de alunos, e do pessoal de monitoria de creche e de monitoria de ensino especial da Secretaria de Educação do município de Mariana. Mariana, Secretaria Municipal de Educação, 2014. Disponível em: http://camarademariana. mg.gov.br/legislacoes/2561/. Acesso em: 5 jan. 2020.

MEDLEY, D. Teacher competency testing and the teacher educator. Charlottesville: Association of Teachers Educators, 1982.

MOURSHED, M.; CHIJIOKE, C.; BARBER, M. How the world's most improved school systems keep getting better. London: Mckinsey \& Company, 2010.

NEVO, D. Normative dimensions of evaluation practice. In: H. J. WALBERG, H. J.. HAERTEL, G. D. (eds.). The international encyclopedia of educational evaluation. Oxford: Pergamon Press, 1990. p. 89-91.

NEVO, D. School-based evaluation: a dialogue for school improvement. Oxford: Pergamon, 1995.

PACHECO, J. A.; FLORES, M. A. Formação e avaliação de professores. Porto: Porto Editora, 1999.

REIFSCHNEIDER, M. B. Considerações sobre avaliação de desempenho. Ensaio: Avaliação e Politicas Públicas em Educação, Rio de Janeiro, v. 16, n. 58, p. 47-58, jan./mar. 2008. https://doi.org/10.1590/S0104-40362008000100004 
SAMPAIO, A. M. M. Demandas de desenvolvimento profissional docente no município de Mariana-MG: PNE (2014-2024) e PME (2015-2024). Dissertação (Mestrado em Educação) - Instituto de Ciências Humanas e Sociais, Universidade Federal de Ouro Preto, Mariana, 2018.

SCRIVEN, M. A unified theory approach to teacher evaluation.

Studies in Educational Evaluation, [s. 1.],, v. 21, n. 2, p. 111-129, 1995. https://doi.org/10.1016/0191-491X(95)00009-J

WORLD BANK. Um ajuste justo: análise da eficiência e equidade do gasto público no Brasil. Brasília, DF, 21 nov. 2017.

\section{Informações sobre os autores}

José Rubens Lima Jardilino: Professor do Programa de Pós-Graduação em Educação da Universidade Federal de Ouro Preto. Pesquisador do Conselho Nacional de Desenvolvimento Científico e Tecnológico - Pq2. Contato: jrjardilino@ufop.edu.br

(iD) http://orcid.org/0000-0003-2394-9465

Ana Maria Mendes Sampaio: Doutoranda pelo Programa de Pós-Graduação em Educação da Universidade Federal de Ouro Preto. Bolsista Coordenação de Aperfeiçoamento de Pessoal de Nível Superior. Contato: anamendessampaio@yahoo.com

(iD) http://orcid.org/0000-0002-9821-911X

Andressa Maris Rezende Oliveri: Doutoranda pelo Programa de Pós-Graduação em Educação da Universidade Federal de Ouro Preto. Bolsista da Fundação de Amparo à Pesquisa do Estado de Minas Gerais. Contato: amarisandressa@gmail.com

(iD) http://orcid.org/0000-0001-9135-6296 